\title{
A FORTIORI: UMA ANÁLISE CRÍTICA DESTE TIPO DE ARGUMENTAÇÃO NA TOMADA DE DECISÃO JUDICIAL
}

\author{
Daniel de Souza Lucas* \\ Mario Cesar da Silva Andrade ***
}

SUMÁRIO: Introdução; 2 O Lugar do Argumento a Fortiori; 2.1 Na Tomada de Decisão em Geral; 2.2 Na Tomada de Decisão por Precedentes; 3 O Argumento a Fortiori; 3.1 A Ideia Básica; 3.2 Alguns Esquemas Básicos; 3.3 Os Problemas dos Esquemas Básicos; 3.4 Um Esquema Alternativo; 4 Um Exemplo Real de Argumento a Fortiori; 5 Considerações Finais; Referências.

RESUMO: O presente artigo pretende investigar a adoção do argumento a fortiori no processo decisório judicial. Essa forma de argumentação seria muito utilizada por permitir que o julgador contorne restrições epistêmicas e normativas. Sustenta-se: o argumento a fortiori é uma forma de instrumentalizar o processo decisório em ambientes de grande incerteza. Metodologicamente, a pesquisa qualitativa bibliográfica utiliza as contribuições teóricas para problematizar o modelo de raciocínio por precedentes preferido por muitos juristas e descrito por Larry Alexander como um modelo fortemente preocupado em garantir que determinado resultado seja produzido pelo precedente. Em conclusão, foi possível verificar que o Superior Tribunal de Justiça argumenta a fortiori com frequência. Tanto que optou-se por estabelecer nesse artigo as bases de um procedimento de análise capaz de identificar na incerteza quais das três diferentes finalidades do argumento está em jogo: ordenação de termos, extração de princípios implícitos ou estabelecimento de métricas comuns.

PALAVRAS-CHAVE: Argumento a fortiori; Decisão judicial; Precedentes.

\section{A FORTIORI: A CRITICAL ANALYSIS OF ARGUMENTATION IN JURIDICAL DECISION-TAKING}

ABSTRACT: Current paper investigates the use of a fortiori arguments in juridical processes. The type of argumentation is highly employed, since judges lessen epistemic and normative restrictions. The a fortiori argument is a way of instrumentalizing the decision process in milieus with deep uncertainties. Qualitative and bibliographic research employs theoretical contributions to problematize the reasoning

\footnotetext{
Mestrando em Teorias Jurídicas Contemporâneas no Programa de Pós-graduação em Direito da Faculdade Nacional de Direito da Universidade Federal do Rio de Janeiro (UFRJ), Brasil. E-mail: daniel.lucas@ufrj.br

** Docente da Universidade Federal de Juiz de Fora/MG (UFJF). Doutorando em Teorias Jurídicas Contemporâneas na Faculdade Nacional de Direito da Universidade Federal do Rio de Janeiro (FND/UFRJ), Brasil.
} 
model by antecedents used by judges. It has been described by Larry Alexander as a model greatly employed to warrant that determined results are produced by the antecedent. One may perceive that the Higher Court of Justice uses the a fortiori argument with frequency. Current article tries to establish the bases of a proceeding of analysis which identifies, within uncertainty, which of the three reasons of the argument is concerned with: the ordination of terms, the extraction of implicit principles or the establishment of common metrics.

KEY WORDS: Argument a fortiori; Judicial decision; Antecedents.

\section{A FORTIORI: UN ANÁLISIS CRÍTICO DE ESTE TIPO DE ARGUMENTACIÓN EN LA TOMA DE DECISIÓN JUDICIAL}

RESUMEN: En el presente artículo se pretende investigar la adopción del argumento a fortiori en el proceso decisorio judicial. Esa forma de argumentación sería muy utilizada por permitir que el juzgador contorne restricciones epistémicas y normativas. Se sustenta: el argumento a fortiori es una forma de instrumentalizar el proceso decisorio en ambientes de gran incertidumbre. Metodológicamente, la investigación cualitativa bibliográfica utiliza las contribuciones teóricas para problematizar el modelo de raciocinio por precedentes preferido por muchos juristas y descripto por Larry Alexander como un modelo fuertemente preocupado en garantizar que determinado resultado sea producido por el precedente. En conclusión, fue posible verificar que el Superior Tribunal de Justicia argumenta a fortiori con frecuencia. Tanto que se optó por establecer en ese artículo las bases de un procedimiento de análisis capaz de identificar en la incertidumbre cuales de las tres diferentes finalidades del argumento están en juego: ordenación de términos, extracción de principios implícitos o establecimiento de métricas comunes.

PALABRAS CLAVE: Argumento a fortiori; Decisión judicial; Precedentes.

\section{INTRODUÇÃO}

Os tribunais argumentam a fortiori, frequentemente? Quem responde afirmativamente entende que essa forma de argumentação é muito utilizada por permitir que o julgador contorne certos tipos de restrições epistêmicas e normativas impeditivas do trato direto da questão. Mas o que há de distintivo nesse tipo de argumento? O primeiro objetivo deste artigo, mais geral, é chamar a atenção da comunidade jurídica para esse tipo de argumento, subestimado em sua potenciali- 
dade, e apresentar os resultados da primeira etapa de uma agenda de pesquisa que pretende investigar a concepção e avaliação dos argumentos a fortiori, a partir da convergência entre as abordagens lógica e dialética de argumentação.

O segundo objetivo, mais específico, é apresentar diferentes esquemas argumentativos $^{03}$ formulados para descrever abstratamente o argumento a fortiori e auxiliar a compreensão de sua finalidade e contexto, tudo para reconstruir um conjunto de argumentos reais formulados pelo Superior Tribunal de Justiça (STJ). Pretende-se evidenciar a utilidade do argumento a fortiori no processo de tomada de decisão, principalmente em ambientes de grande incerteza.

Em geral, argumentos a fortiori são associados a dois princípios interpretativos ou máximas: qui potest plus potest minuse qui non potest minus non potest plus. O primeiro estabelece que aquele que pode (explicitamente) mais, também pode (implicitamente) menos; e o segundo afirma que aquele que não pode (por explicitamente proibido) menos, não pode mais $^{04}$. Esses dois princípios incorporam o esquema argumentativo para garantir a validade de uma conclusão que se baseia na comparação com outra conclusão obtida em caso semelhante.

Esta característica do argumento a fortiori, explorada nos processos decisórios em geral, sistematiza um processo de tomada de decisão em particular em que o resultado das decisões é comparado para ser o resultado correto. Larry Alexander $^{05}$ descreveu esse modelo de raciocínio por precedente, como aquele cuja força do precedente se situa entre o extremo muito fraco, e não restritivo, do modelo persuasivo, e o extremo muito forte, e quase-legislativo, do precedente como regra. De acordo com o pure result model, tomadores de decisão em casos subsequentes perdem a liberdade decisória característica do precedente persuasivo se, e somente $s e$, o caso sob exame exigir, a fortiori, que o resultado (incorreto ${ }^{06}$ ) do caso precedente seja o mesmo. ${ }^{07}$

A primeira seção deste trabalho é dedicada à discussão do lugar do argumento a fortiori na tomada de decisão. A segunda aprofunda-se nas diferentes formas de estruturar e avaliar o argumento. Essa seção parte de uma proposta de esquema

\footnotetext{
${ }^{03}$ Representações em que se destaca o aspecto geral das partes essenciais do argumento: as premissas e a conclusão.

${ }^{04}$ D'ALMEIDA, Luís Duarte. Arguing a fortiori. The Modern Law Review, v. 80, n. 2, 2016, p. 231.

${ }^{05}$ ALEXANDER, Larry. Constrained by precedent. South California Law Review, v. 63, 1989, p. 28-29.

${ }^{06} \mathrm{O}$ termo incorreto é usado por Alexander para transmitir a ideia de que esse modelo tem, assim como o modelo de precedente como regra, a capacidade de fazer com que o tomador de decisão escolha o resultado que não lhe parece ser o melhor dadas as circunstâncias do caso.

${ }^{07}$ ALEXANDER, Larry. Op. cit., 1989, p. 30.
} 
básico e agrega uma crítica que problematiza a principal característica do argumento a fortiori: a forma de ranquear $n$ casos a partir da mesma métrica. Na terceira seção, são reconstruídos e analisados os argumentos reais elaborados pela Sexta Turma do STJ, que chamam a atenção para a importância de estudar o argumento a fortiori e indicam a pertinência da agenda de pesquisa.

\section{O LUGAR DO ARGUMENTO A FORTIORI}

A maioria das decisões judiciais envolve a manipulação de uma variedade de formas de argumentos. Em geral, essa manipulação corresponde a um dentre dois objetivos possíveis: ou ela procura equilibrar diferentes alternativas para escolher aquela que se espera ser a melbor para resolver o problema em questão, ou a manipulação procura escolher aquela que seja a menos negativa ou adversa. Ambas alternativas, apesar de descreverem diferentes maneiras de pensar, explicitam a preocupação em procurar qual a razão mais forte que está em jogo. $\mathrm{O}$ argumento a fortiori é uma poderosa ferramenta para o processo deliberativo nesses moldes; ele pode ser eficaz como estratégia de argumentação a induzir acordos e resultados imparciais.

No entanto, ele também pode proporcionar alguns usos tendenciosos, como quando apela à autoridade para impor uma ideia ou forçar uma decisão em determinado sentido. Usos tendenciosos têm efeito direto na objetividade e imparcialidade da tomada de decisão. A seguir, apresenta-se uma análise de como argumentos a fortiori funcionam em processos de tomada de decisão. Não só oferece uma concepção e usos diferentes deste tipo de argumento baseado na literatura contemporânea e clássica, mas abrange outras questões, como análise e avaliação.

\subsection{NA TOMADA DE DECISÃO EM GERAL}

Como destaca Sandra Clemencia Valencia Martínez ${ }^{08}$, o processo de tomada de decisão pode ser realizado individual ou coletivamente. Em ambos, os atos de fala dos tomadores de decisão são assumidos como proposições que, em tomadas de de-

\footnotetext{
${ }^{08}$ VALENCIA MARTÍNEZ, S. The use of arguments a fortiori in decision making. 2016, p. 02. Disponível em: $<$ https://scholar.uwindsor.ca/cgi/viewcontent.cgi?referer =https://scholar.google.com.br/\&httpsredir = 1\&article $=2447 \&$ context $=$ ossaarchive $>$. Acesso em: 13 maio 2018 .
} 
cisão coletiva, podem ser dialeticamente embaralhadas, como alternativas possíveis em um contexto específico, que não consegue ser alheio a convenções linguísticas, aspectos sociais, institucionais, culturais e cognitivos dos seus componentes. Dentro da instituição judiciária, dado o peso que coerência e consistência detêm para a credibilidade do sistema jurídico, pensar o processo decisório como inevitavelmente coletivo - já que decisões anteriores monocráticas ou colegiadas influenciam, em menor ou maior grau, decisões posteriores - abre espaço para uma análise que consegue transcender as contingências estabelecidas pelo direito processual positivo para abrir espaço à discussão acerca de como os ideais de coerência e consistência são perseguidos no Direito.

Neste sentido, Richard D. Rieke et al..$^{09}$ identificam que o processo de tomada de decisão coletiva ocorre em duas fases principais. A primeira, a fase de preparação do caso, se subdivide em três estágios, em que o primeiro deles está diretamente ligado à determinação clara do problema a ser enfrentado e à seleção da proposição que será defendida. Esse estágio compreende oito etapas alternativas que buscam: (i) estabelecer a pergunta que representa o problema; (ii) identificar os objetivos e valores diretamente relacionados ao problema; (iii) procurar dentre as decisões alternativas, aquela que é a mais atraente; (iv) pesar os custos e os riscos de cada alternativa; (v) pesquisar e filtrar as informações disponíveis em relação ao problema; (vi) examinar criticamente as alternativas, levando em consideração as etapas ii, iii e v; (vii) identificar os pontos cegos, como vieses ou preconceitos ocultos dentro de alternativas; e (viii) selecionar a proposição mais razoável. ${ }^{10}$

No segundo estágio é avaliada a força da proposição selecionada, pesando os argumentos a favor ou contra a proposição. A importância desse passo se deve ao fato de que ao olhar os dois lados, o autor da proposição pode descobrir quais questões de fato ou de direito provavelmente serão as mais cruciais. O terceiro estágio torna explícitos os critérios usados pelo autor da proposição na mensuração de sua força. São esses critérios que permitirão que essa proposição seja avaliada por terceiros, e o conjunto de avaliações das diferentes proposições permitirá a seleção da melhor dentre elas. ${ }^{11}$

Com o encerramento da preparação do caso, vem a segunda fase, a de cons-

\footnotetext{
${ }^{09}$ RIEKE, Richard D.; SILLARS, Malcolm Osgood; PETERSON, Tarla Rai. Argumentation and critical decision making. New York: Longman, 1997.

${ }^{10}$ VALENCIA MARTÍNEZ, S. C. Op. cit., 2016, p. 03.

${ }^{11}$ Ibidem, p. 03.
} 
trução do caso, que tem o objetivo de desenhar a argumentação do autor da proposição e enfoca os aspectos relacionados aos argumentos e contra-argumentos que serão estrategicamente usados na defesa ou ataque de cada proposta formulada na primeira fase, estabelecendo os pontos de partida como: as interpretações compartilhadas, suposições, fatos, probabilidades e lugares-comuns. Para isso, é importante identificar o contexto em que a proposição será discutida e o tipo de público envolvido na deliberação ${ }^{12}$.

Esse desenbo de processo decisório transcendental, fortemente influenciado pela estrutura pragma-dialética de Frans H. van Eemeren ${ }^{13}$, parte do pressuposto de que elementos retóricos e dialéticos interagem na tomada de decisão. Ou seja, ele reconhece que outros fatores, além do mérito da proposição, devem ser levados em consideração, fatores como: a ordem e a maneira de estruturar e apresentar argumentos com vistas a obter adesão, e a maneira de acordo com a qual se distribui o ônus da prova entre os participantes do processo.

Essa concepção de processo decisório transcendental é relevante, porque justifica a análise das possibilidades de manobras que o uso dos argumentos a fortiori proporciona no processo de tomada de decisão. Com o desenho em mente, fica mais fácil questionar a evidência da relação que se forma entre a proposição que está sob comparação e a proposição que lhe serve de paradigma; ele ajuda a entender como o argumento a fortiori pode ser adaptado às demandas da audiência, e, também, a entender que o autor da proposição pode estabelecer um movimento de adaptação, em cada estágio do processo, para alcançar o seu propósito. ${ }^{14}$

\subsection{NA TOMADA DE DECISÃO POR PRECEDENTES}

Larry Alexander ${ }^{15}$ defende que o argumento a fortiori é capaz de descrever o modelo de precedente com o qual a maioria dos juristas está mais familiarizada, e que juristas como Edward Levi, Steve Burton, Brian Simpson, Joseph Raz, Michael Moore e, talvez com algumas adaptações, Ronald Dworkin preferem. Um modelo cuja força varia entre a fraqueza extrema de um modelo persuasivo, que não tem a capacidade de constranger o tomador de decisão, e a força extrema de uma decisão

12 Ibidem, p. 03-04.

${ }^{13}$ VAN EEMEREN, Frans H. Strategic maneuvering in argumentative discourse: Extending the pragma-dialectical theory of argumentation. Amsterdam: John Benjamins Publishing, 2010, p. 83.

${ }^{14}$ VALENCIA MARTÍNEZ, S. C. Op. cit., 2016, p. 04.

${ }^{15}$ ALEXANDER, Larry. Op. cit., 1989, p. 28-29. 
judicial que, ao funcionar como regra, torna a atividade das cortes superiores quase-legislativa. Alexander ${ }^{16}$ considerou que esse modelo está centrado no resultado, sendo chamado por ele de pure result model. Em sua forma mais simples, a forma operacionalizada por este tipo de argumento, tomadores de decisão em casos subsequentes perdem a liberdade decisória característica do precedente persuasivo se, e somente se, o caso sob exame exigir, a fortiori, que o resultado seja o mesmo do caso precedente, ainda que esse resultado seja considerado incorreto pelos atuais tomadores de decisão.

Ou seja, seguir um precedente, nestes termos, implica decidir em favor da parte análoga à parte vencedora no caso precedente, simplesmente porque o resultado do caso sob análise é tão forte quanto, ou mais forte que, o resultado alcançado no caso precedente. Qualquer regra declarada no corpo do precedente é irrelevante para este modelo, que tende a controlar todos os casos a fortiori a partir de um caso precedente, mesmo que eles estejam fora do alcance da regra declarada no precedente. ${ }^{17}$ Casos precedentes só não controlam o resultado alcançado pelos tomadores de decisão subsequentes, quando o caso sob análise foi mais fraco. Porém, o que é determinante para a atribuição do status de precedente a uma decisão? Como avaliar a força (ou fraqueza) do precedente nesse modelo? Como determinar o alcance da regra do precedente? Essas são questões práticas importantes para a compreensão desse modelo.

De acordo com o modelo de Alexander ${ }^{18}$, a determinação do status de precedente pode ser extraída do esquema de argumentação que ele formula. Estar-se-á diante de um precedente quando: um tribunal hierarquicamente superior tenha declarado a parte $P$ vencedora do caso, e que todos os casos caracterizados por $A \mathrm{e}$ $B$ deveriam ser decididos em favor da parte análoga à $P$. Como avaliar a força desse precedente? Alexander ${ }^{19}$ avança na descrição desse modelo indicando que, quando um caso subsequente apresenta, por exemplo, os fatos $A, B, C$ e $E$, além da força $N$ (a força que qualquer caso precedente carrega em função do caráter persuasivo que desempenha ou do dever de tratar casos semelhantes da mesma maneira), os tomadores de decisão poderiam ignorar a regra do precedente (se constatados os fatos $A$ e $B$, decidir a favor de $P$ ), decidindo contra a parte análoga à $P$ se, e somente se,

\footnotetext{
${ }^{16}$ Ibidem, p. 30 .

${ }^{17}$ Ibidem, p. 30.

${ }^{18}$ Ibidem, p. 30.

${ }^{19}$ Ibidem, p. 30.
} 
a ausência de $D$ e a presença de $E$ e $N$ tornam o caso subsequente mais fraco para essa parte análoga.

O alcance da regra do precedente nesse modelo não é exclusivamente uma operação de extração do significado da regra, ele é mais aberto que isso. Alexander ${ }^{20}$ o descreve da seguinte forma: se a presença do fato $E$ for uma razão mais forte para decidir a favor da parte análoga à $P$, do que a presença do fato $D$, então o modelo centrado no resultado obrigará a decisão em favor da parte análoga à $P$, mesmo que os tomadores de decisão acreditem que a força persuasiva $N$, nessas circunstâncias, desfavorece o resultado em favor da parte análoga à $P$.

Em resumo, o uso de argumentos a fortiori na tomada de decisão por precedentes é uma maneira de atribuir conteúdo ao princípio de acordo com o qual casos semelhantes devem ser tratados da mesma forma (treat like cases alike). Como a maior crítica a esse princípio é a de que todos os casos são parecidos em alguns aspectos, mas não em outros, o modelo de precedente focado no resultado se esforça para estabelecer, substancialmente, o que importa para aferir semelhança entre os casos: razões derivadas de fatos que possuam, no mínimo, igual força e apontem para adequação de um resultado análogo ao resultado no caso precedente. ${ }^{21}$

Qual o principal problema que essa formulação enfrenta?

A dificuldade parece ser determinar uma metodologia que permita aferir que o caso subsequente é, a fortiori, controlado pelo resultado do precedente. Isso é importante, porque o objetivo de um sistema jurídico que adota a doutrina do precedente é mitigar a possibilidade de que decisores possam, a partir de princípios políticos e/ou morais, decidir em favor de qualquer uma das partes; mas é contraintuitivo que um caso que leva em conta princípios políticos e/ou morais corretos, e por isso deva ser decidido em favor da parte $Q$, seja, por influência de razão extraída de uma decisão anterior e invocada a fortiori, decidida em favor da parte $P{ }^{22}$

$\mathrm{O}$ uso de argumentos a fortiori na tomada de decisão por precedentes requer uma forma de comparação e atribuição de pesos aos fatos que não é caso a caso como na analogia, mas uma comparação de $n$ casos na métrica comum assumida como metodologia para comparação e atribuição de pesos a uma categoria de fatos. Essa diferença em relação à analogia faz com que a metodologia tenha que

\footnotetext{
${ }^{20}$ Ibidem, p. 30.

${ }^{21}$ ALEXANDER, Larry. Op. cit., 1989, p. 30.

${ }^{22}$ Ibidem, p. 34.
} 
assumir um único princípio-mestre, ao qual Alexander ${ }^{23}$ chama metaforicamente de moeda. Um princípio-mestre que tenha a qualidade de ser geralmente aceito por todos e seja capaz de atribuir pesos de maneira intercambiável entre vários fatos.

Alexander ${ }^{24}$ reconhece que o raciocínio moral é muito mais complexo do que essa metáfora; uma decisão no caso subsequente pode alterar a extensão do princípio ou política estabelecida na decisão do caso precedente. Assim, conclui que o modelo de doutrina do precedente que foca no resultado, estabelecendo uma métrica comum para a comparação de casos, é operacionalizado por argumentos $a$ fortiori, e diz aos decisores subsequentes algo como se um caso: caso haja um caso precedente em que o saldo da consideração de todos os fatos na métrica comum $R$ foi favorável à parte $P$, por exemplo, em dez unidades, e, mesmo assim, o caso tenha sido decidido em favor da parte $Q$, então, todos os casos em que o saldo de $R$ for menor ou igual a dez unidades em prol da parte $P$ deverão ser decididos a favor de $Q$, não importando o quão semelhante seja o caso $n$ em relação ao precedente.

A importância do precedente nesse modelo está no estabelecimento de uma métrica comum de ranqueamento de casos, e não no estabelecimento de condições de semelhança. Ranquear os casos a fortiori nada mais é do que comparar, nessa métrica comum, o saldo obtido entre dois casos e assim decidir a favor do demandante ou do réu conforme o precedente. Vale destacar que uma métrica comum transcendente pode ainda permitir que um caso de responsabilidade extracontratual, por exemplo, seja um precedente para um caso de quebra de contrato que não tenha qualquer semelhança com ele. ${ }^{25}$

\section{O ARGUMENTO A FORTIORI}

A seção anterior mostrou que Rieke e Van Eemeren são figuras-chave para mostrar a importância do a fortiori no processo de tomada de decisão em geral, e para sofisticar a avaliação desse tipo de argumento a partir da introdução de variáveis, como a violação de regras processuais ou a consideração de fatores contextuais retóricos, como linguagem ou audiência. A seção anterior mostrou também que Alexander conseguiu descrever um processo de tomada de decisão por precedentes,

\footnotetext{
23 Ibidem, p. 35.

24 Ibidem, p. 35.

25 ALEXANDER, Larry. Op. cit., 1989, p. 35.
} 
reconhecido como o mais intuitivo, que usa francamente o argumento a fortiori na tentativa de promover a consistência das decisões no Direito.

Além disso, a seção anterior introduziu também a ideia de que a obra de Van Eemeren é importante para a avaliação de usos falaciosos do argumento a fortiori porque, enquanto construção teórica, seria possível perceber manobras estratégicas ao longo da argumentação. ${ }^{26} \mathrm{~A}$ seção anterior chamou a atenção para o entorno do argumento a fortiori. No entanto, importa analisar o argumento a fortiori enquanto produto, ou seja, o mais importante é trazer a tradição lógica para o primeiro plano e destacar as características distintivas desse tipo de argumento: os esquemas de argumentação. Isso é fundamental para a reconstrução dos argumentos reais dos tribunais, embora a tradição da comunicação e do debate representada por Rieke e a Pragma-dialética representada por Van Eemeren sejam relevantes formas de ressaltar o fato de que certos elementos contextuais, em casos reais, impactam no resultado da argumentação.

\subsection{A IDEIA BÁSICA}

Para Fabrizio Macagno e Douglas Walton ${ }^{27}$, o argumento a fortiori é um tipo de argumento analógico. Em ambos os tipos, o intérprete pretende aplicar uma regra que não está expressa ou pressupor uma razão jurídica de um caso-fonte que resolve o problema do caso-alvo. Porém, existe uma diferença relevante: o argumento a fortiori não pretende estabelecer uma relação de equivalência entre os casos, como pretende a analogia ${ }^{28}$, e sim uma relação de vinculação, de acordo com a qual, se um predicado não pode ser atribuído a $P$ em função de uma grandeza escalar $R$, então, o predicado também não pode ser atribuído à $Q$ em função da posição relativa de $Q$ e $P$ nessa escala.

Além disso, diferentemente das analogias que podem ser usadas para especificar as propriedades de um predicado ou estender a atribuição de predicados a

\footnotetext{
${ }^{26}$ Sobre as manobras estratégicas, ver seção 6 de Valencia Martínez. Op. cit., 2016.

${ }^{27}$ MACAGNO, Fabrizio; WALTON, Douglas. Arguments of statutory interpretation and argumentation schemes. International Journal of Legal Discourse, v. 2, n. 1, 2017, p. 62.

${ }^{28}$ Para Macagno e Walton, analogias no Direito estão baseadas na pretensão de argumentar a partir de princípios gerais que conectam espécies de entidades a gêneros de entidades a partir da máxima de acordo com a qual o que é predicado das partes (neste caso parte essencial, a espécie) é também predicado do todo (neste caso o todo essencial, o gênero). Quando, em uma analogia, o gênero $G$ é abstraído com base na propriedade $A$ que predica a espécie $P$, então, é possível transmitir $A$ para $Q$ - outra espécie do gênero -, quando há semelhança essencial entre as duas espécies. Sob a perspectiva de $A, Q$ é como se fosse $P$. Analogias criam subcategorias implícitas. MACAGNO, Fabrizio; WALTON, Douglas. Op. cit., 2017, p. 59-61.
} 
outras espécies que podem ser reunidas em gêneros ${ }^{29}$, argumentos a fortiori podem ser usados para: (i) determinar o grau de posse de um predicado a partir do contraste entre dois ou mais sujeitos, coisas ou eventos; (ii) fortalecer uma posição; (iii) examinar a plausibilidade de adjudicação de uma característica ou propriedade; (iv) ranquear os melhores exemplos de uma classe ou categoria; e (v) ajudar a escolher entre dois valores ou alternativas. ${ }^{30}$

Já Allen Wiseman ${ }^{31}$ defende que, em geral, esse tipo de argumento funciona a partir de inferências escalares, de afirmações da verdade de uma proposição que trata do estabelecimento das posições relativas dos objetos comparados em determinada escala. Propriedade essa que leva à suposição de que existe uma condição para a comparação a fortiori: perceber, entre os objetos que se pretende comparar, não uma característica relevante que faz deles espécies de um mesmo gênero, e sim uma métrica comum que permite seu ranqueamento em termos de qualidade, quantidade, diferença específica ou preferência.

Pensar o argumento a fortiori como um tipo de analogia à moda de Macagno e Walton limita as possibilidades de explorar e destacar dois usos particularmente importantes do argumento a fortiori no Direito: o ranqueamento de casos em uma escala comum e o auxílio à escolha de uma entre duas opções possíveis. Assume-se que o argumento a fortiori não é um argumento analógico, apesar de se valer de semelhanças, pelo fato desse tipo de argumento não pretender, nem estender o tratamento jurídico previsto para uma categoria jurídica a elementos não previstos expressamente, em função de características relevantes compartilhadas, nem extrair um princípio implícito aplicável ao gênero, cujas espécies são os casos fonte e alvo.

A ideia básica do argumento a fortiori é a de que, se um predicado $S$ não puder ser atribuído a $P$, indivíduo ou categoria de indivíduos, com maior probabilidade de predicação, então $S$ também não poderá ser atribuído a $Q$, indivíduo ou categoria de indivíduos com menor probabilidade de predicação. De forma equivalente, se um predicado $S$ puder ser atribuído a $P$, indivíduo ou categoria de indivíduos com menor probabilidade de predicação, então $S$ deve ser atribuído a $Q$, indivíduo ou categoria de indivíduos com maior probabilidade de predicação. ${ }^{32}$

\footnotetext{
${ }^{29}$ MACAGNO, Fabrizio; WALTON, Douglas. Op. cit., 2017, p. 61.

${ }^{30}$ VALENCIA MARTÍNEZ, S. C. Op. cit., 2016, p. 05.

${ }^{31}$ WISEMAN, Allen. A contemporary examination of the a fortiori argument involving jewish traditions. 2010, $\mathrm{p}$. 04. 257f. Tese de Doutorado em Filosofia. Universidade de Waterloo, Ontario. Disponível em: < https://uwspace.uwaterloo.ca/bitstream/handle/10012/5038/A\%20Contemporary $\% 20$ Examination $\% 20 \mathrm{of} \% 20$ the $\% 20 \mathrm{~A} \% 20$ Fortiori\%20Argument\%20Involving\%20Jewish\%20Traditions.pdf?sequence=1>. Acesso em: 22 maio 2018.

${ }^{32}$ MACAGNO, Fabrizio; WALTON, Douglas. Op. cit., 2017, p. 61-62.
} 


\subsection{ALGUNS ESQUEMAS BÁSICOS}

Como visto, a ideia básica é a de que o argumento a fortiori não pretende estabelecer uma relação de equivalência entre os casos, e sim uma relação de vinculação. Para Macagno e Walton ${ }^{33}$, essa forma de argumentar seria orientada pelo seguinte esquema:

\section{(Esquema 1)}

\begin{tabular}{|l|l|}
\hline 1. Nenhuma norma prevê que $x$ faz parte da categoria $Q$. & (premissa alvo) \\
\hline 2. Se $x$ é $P$, então $x$ deve ser/é $S$. & (premissa propriedade) \\
\hline $\begin{array}{l}\text { 3.P e } Q \text { fazem parte/são um subconjunto do mesmo gênero } \\
\text { funcional } G \text { que motiva } S .\end{array}$ & (premissa de similaridade) \\
\hline 4. Se $x$ é $G$, então $x$ deve ser/é $S$. & (premissa espécie-gênero) \\
\hline 5. $Q$ pertence a $G$ com mais razão do que $P$ pertence a $G$. & (premissa $a$ fortiori) \\
\hline Então, & \\
\hline 6. Se $x$ é $Q$, então $x$ deve ser/é $S$. & (conclusão) \\
\hline
\end{tabular}

Macagno e Walton ${ }^{34}$ oferecem apenas um esquema de argumento a fortiori, apesar de reconhecerem a existência de dois tipos distintos usados, quando, por um lado, se pretende impor uma condição vantajosa como um direito, ou, por outro, se pretende estabelecer uma condição desfavorável, como um dever. No primeiro caso, o argumento se trata de um majori ad minus, um argumento que vai do maior para o menor, e, no segundo caso, o argumento é um menor ad maius, um argumento que vai do menor para o maior. Essa distinção, feita originalmente por Riccardo Guastini (2011), evidencia a diferença entre os predicados construtivos (direitos) e os predicados destrutivos (obrigações e deveres). Se uma ação é permitida, qualquer ação similar vista como melhor em relação aos valores que o direito protege também será, a fortiori, permitida. Se uma ação é proibida, então qualquer ação que seja similar, mas pior, em relação aos valores que o direito protege, também será, $a$ fortiori, proibida.

Outro aspecto relevante para a análise do argumento a fortiori é a de que esse tipo de raciocínio se baseia na propriedade juridicamente relevante de uma

\footnotetext{
33 Ibidem, p. 63.

34 Ibidem, p. 63-64.
} 
ação, propriedade que pode ser negativa ou positiva. Algo considerado como juridicamente ruim é avaliado como negativo, e a qualidade de "ser pior do que" caracteriza-se pela constatação de um grau equivalente ou mais alto dessa característica negativa. Nesse viés negativo, a qualidade de "ser melhor do que" caracteriza-se pela constatação de um menor grau dessa mesma característica. Quando o viés é positivo, "ser melhor do que" é consequência da constatação de um grau mais alto da propriedade que caracteriza a bondade da ação, enquanto "ser menor do que" é consequência da constatação de seu menor grau. ${ }^{35}$

Avi Sion ${ }^{36}$ explora essas possibilidades e descreve quatro possíveis esquemas de argumento a fortiori:

\begin{tabular}{|c|c|c|}
\hline Esquema & Positivo (inclui) & Negativo (exclui) \\
\hline \multirow{5}{*}{ Subjetivo } & (Esquema 2) & (Esquema 3) \\
\hline & $\begin{array}{l}\text { 1. } P \text { é mais } R \text { do que (ou tão } R \text { quanto) }{ }^{1} Q \\
\text { (é } R \text { ) }\end{array}$ & $\begin{array}{l}\text { 1. } P \text { é mais } R \text { do que (ou tão } R \text { quanto) } \\
\text { Q (é } R \text { ). }\end{array}$ \\
\hline & 2. $Q$ é $R$ o suficiente para ser $S$. & 2. $P$ não é $R$ o suficiente para ser $S$. \\
\hline & Por consequência, & Por consequência, \\
\hline & $\begin{array}{l}\text { 3. } P \text { é, com mais razão (ou igual razão), } R \text { o } \\
\text { bastante para ser } S \text {. }\end{array}$ & $\begin{array}{l}\text { 3. Com mais razão (ou igual razão), } Q \\
\text { não é } R \text { o suficiente para ser } S \text {. }\end{array}$ \\
\hline \multirow{5}{*}{$\begin{array}{l}\text { Predica- } \\
\text { tivo }\end{array}$} & (Esquema 4) & (Esquema 5) \\
\hline & $\begin{array}{l}\text { 1. Mais (ou tanto) } R \text { é necessário para ser } P \text {, } \\
\text { do que para ser } Q \text {. }\end{array}$ & $\begin{array}{l}\text { 1. Mais (ou tanto) } R \text { é necessário para } \\
\text { ser } P \text {, do que para ser } Q \text {. }\end{array}$ \\
\hline & 2. $S$ é $R$ o suficiente para ser $P$; & 2. $S$ não é $R$ o suficiente para ser $Q$. \\
\hline & Portanto, & Portanto, \\
\hline & $\begin{array}{l}\text { 3. Com mais razão (ou igual razão), } S \text { é } R \text { o } \\
\text { suficiente para ser } Q \text {. }\end{array}$ & $\begin{array}{l}\text { 3. Com mais razão (ou igual razão), } S \\
\text { não é } R \text { o suficiente para ser } P \text {. }\end{array}$ \\
\hline
\end{tabular}

Ao centrar a argumentação no sujeito, o esquema de Sion consegue alcançar uma conclusão sólida sobre a vinculação entre $P$ e $Q$, sem afirmar o quantum de característica $R$ o sujeito $P$ possui para receber o predicado. Ou seja, se a determinação do quantum de $R$ em $P$ fosse uma restrição epistêmica para a tomada de decisão, seria possível contorná-la a partir da afirmação descritiva ou normativa que condiciona a predicação em função da posição relativa do $R$ de $P$. Por exemplo, se é

\footnotetext{
35 Ibidem, p. 64.

${ }^{36}$ SION, Avi. A Fortiori Logic: innovations, history and assessments. Genebra: Avi Sion, 2013, p. 21-25.
} 
certo que Jack pode correr mais rápido do que Jill, disso se segue que, se Jill pode correr a uma velocidade tal que percorre uma milha em menos de 15 minutos, então certamente Jack poderá fazer o mesmo. Ao passo que, se Jack não puder percorrer uma milha em menos de 15 minutos, então, Jill também não poderá. ${ }^{37}$ Uma afirmação como essa, usando os esquemas 2 e 3 , resultaria nos dois seguintes tipos distintos de argumentos:

\section{(Argumento 1)}

1. Jack $(\mathrm{P})$ pode correr mais rápido $(\mathrm{R})$ do que Jill $(\mathrm{Q})$;

2. Jill (Q) pode correr uma milha em menos de 15 minutos (S); Então,

3. Jack (P) é, com mais razão, veloz o bastante (R) para correr uma milha em menos de 15 minutos (S).

\section{(Argumento 2)}

1. Jack $(\mathrm{P})$ pode correr mais rápido $(\mathrm{R})$ do que Jill $(\mathrm{Q})$;

2. Jack (P) não pode correr uma milha em menos de 15 minutos (S);

Então,

3. Com mais razão, Jill (Q) não é veloz o bastante (R) para correr uma milha em menos de 15 minutos (S).

Já a argumentação centrada no predicado permite alcançar uma conclusão sólida por uma segunda via: $R$ é predicado de sujeitos não especificados na premissa (1) e um predicado também de $S$, sendo $S$ uma instância ${ }^{38}$ da classe de sujeitos não especificada na premissa maior. ${ }^{39}$ Por exemplo, considerando que é preciso mais força para levantar 50 quilos do que 30 quilos, se alguém consegue levantar 50 quilos, então certamente poderá levantar 30. Ao passo que se alguém não puder levantar 30 quilos, então não poderá levantar $50 .{ }^{40}$ Uma afirmação como essa, usando os esquemas 4 e 5, resultaria nos seguintes tipos distintos de argumentos:

\footnotetext{
37 SION, Avi. Op. cit., 2013, p. 21.

${ }^{38}$ As instâncias de uma classe compartilham o mesmo conjunto de atributos, embora possam ser diferentes quanto ao conteúdo desses atributos, cf. SION, Avi. Op. cit., 2013.

39 SION, Avi. Op. cit., 2013, p. 22-23.

${ }^{40}$ Ibidem, p. 22.
} 
(Argumento 3)

1. Mais força (R) é necessária para levantar 50 quilos (P), do que para levan$\operatorname{tar} 30$ quilos (Q).

2. Alguém (S) é forte (R) o suficiente para levantar 50 quilos (P).

Então,

3. Com mais razão, esse alguém (S) é forte (R) o suficiente para ser levantar 30 quilos (Q).

(Argumento 4)

1. Mais força (R) é necessária para levantar 50 quilos (P), do que para levan$\operatorname{tar} 30$ quilos (Q).

2. Alguém (S) não é forte (R) o suficiente para levantar 30 quilos (Q). Então,

3. Com mais razão, esse alguém (S) não é forte (R) o suficiente para se levantar 50 quilos (P).

Esses quatro esquemas de $\operatorname{Sion}^{41}$ são efetivamente quatro tipos distintos de um argumento a fortiori, uma vez que a ordem dos termos difere significativamente caso a caso. A diferença entre as formas subjetiva e predicativa é chamada de diferença de estrutura. A diferença entre o viés positivo e negativo é chamada de diferença de polaridade. E a diferença entre os estados (moods), que podem ser do menor para maior ou do maior para menor é chamada de diferença de orientação. Às vezes essa diferença de direção é declarada em latim, como a minori ad majus e a majori ad minus.

\subsection{OS PROBLEMAS DOS ESQUEMAS BÁSICOS}

O primeiro deles é a semelhança conceitual e analítica do argumento $a$ fortiori e da analogia iuris no marco teórico de Macagno e Walton ${ }^{42}$. Como a ideia básica desse tipo de analogia seria a de abstrair do Direito um princípio implícito (relação) aplicável a um caso não expressamente previsto pelo sistema jurídico, e a ideia básica do argumento a fortiori seria a de aplicar uma regra que não está expressa ou pressupor uma razão jurídica de um caso-fonte que resolve o problema

\footnotetext{
${ }^{41}$ Ibidem, p. 23.

${ }^{42}$ MACAGNO, Fabrizio; WALTON, Douglas. Op. cit., 2017, p. 60.
} 
do caso-alvo ${ }^{43}$, ou a distinção é desnecessária, ou os dois esquemas são rivais. Compare-se os dois esquemas:

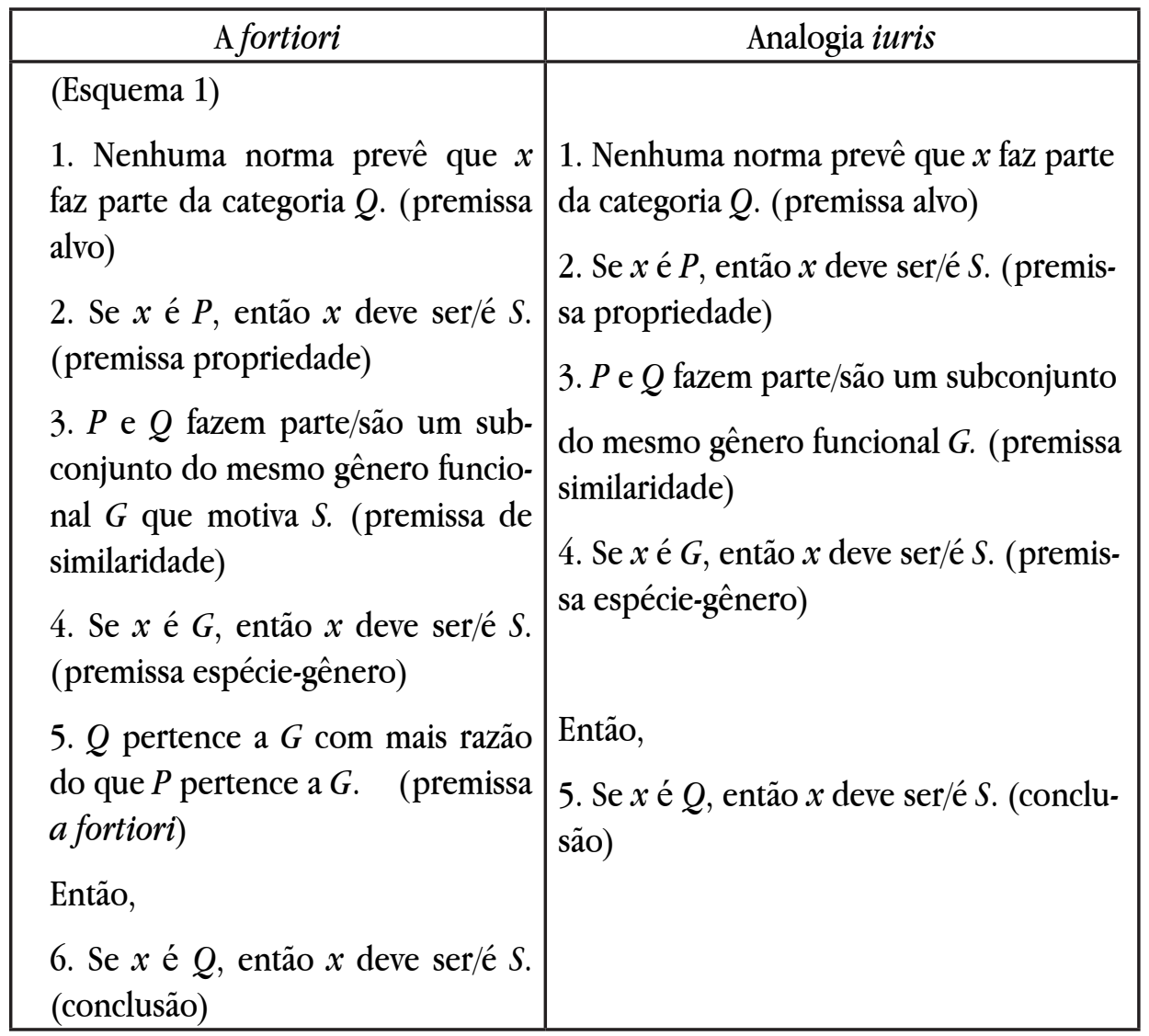

O esquema de argumento a fortiori adotado por Macagno e Walton só tem duas diferenças em relação ao esquema de analogia iuris: o argumento a fortiori afirma a similaridade apelando ao motivo $S$ de existir um gênero $G$, o que a analogia não faz (premissa 3); e o argumento a fortiori deixa explícito que $Q$ e $P$ são espécies do gênero $G$, o que está apenas implícito na analogia (premissa 5). E essas diferenças a maior tornam o argumento a fortiori excessivamente exigente, em comparação ao argumento analógico. Não haveria razão para preferir a argumentação a fortiori, se a solidez da conclusão pode ser alcançada com menos informações, passos e compromisso do autor do argumento com o futuro (a afirmação de $S$ motiva $G$ pode ser

\footnotetext{
43 Ibidem, p. 62.
} 
uma afirmação difícil de fazer ou indesejada no contexto judicial).

O segundo problema é a crítica de d'Almeida ${ }^{44}$ aos esquemas propostos por Sion. Esquemas que, segundo ele, trabalham a ideia de que o argumento a fortiori é um argumento apto a ordenar os termos $P, Q$ e $S$.

Para d'Almeida ${ }^{45}$, os esquemas de Sion não observam o principal motivo para o uso de um argumento a fortiori: a escassez de informações. Ele considera que apenas $P$ e $Q$ estão sendo ordenados, porque, se fosse possível de antemão identificar a relação entre esses dois termos - o que nos exemplos de Sion correspondem às primeiras premissas dos quatro argumentos -, então não seria necessário recorrer ao termo $S$ na escala $R$ para ordenar $P$ e $Q$.

Ele utiliza o exemplo de argumento a fortiori dado por David Daube: "aqui

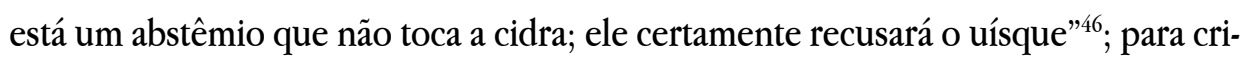
ticar a visão de que o argumento a fortiori deixa explícita a relação entre os sujeitos e o predicado. O argumento de Daube pode ser reconstruído como um quase-silogismo e, neste sentido, d'Almeida tem razão, não há nada de a fortiori nele. Veja-se:

(Argumento 5)

1. Ele é abstêmio.

2. Ele não tocou na cidra.

Então,

3. Ele não irá tocar (S) no uísque $(\mathrm{Q})$.

Ele defende que a imprecisão do argumento de Daube decorre da desnecessidade de utilizar a cidra ou qualquer outra bebida alcoólica como parâmetro de comparação, uma vez que fica claro a partir da constatação da abstemia que qualquer bebida alcoólica será recusada. D'Almeida entende que um "argumento" a fortiori típico (ou mais precisamente uma inferência a fortiori típica) não deixa explícita a relação entre sujeitos e predicado. De maneira que a força retórica desse tipo de argumento está em afirmar apenas que, se ele não toca a cidra, com mais razão não tocará o uísque (2016, p. 203-204). Dizer algo do tipo:

\footnotetext{
${ }^{44}$ D'ALMEIDA, Luís Duarte. Op. cit., 2016, p. 206.

45 D'ALMEIDA, Luís Duarte. Op. cit., 2016.

${ }^{46}$ Ibidem, p. 203.
} 


\section{(Argumento 6)}

1. Menos álcool (R) é necessário na cidra (P), do que no uísque (Q).

2. Ele não tocou (S) na cidra (P).

Então,

3. Com mais razão, ele não irá tocar (S) no uísque (Q).

Também enfraqueceria o argumento a fortiori porque o excesso de informação (premissa 1) permitiria extrair a relação entre sujeitos e predicado: o teor de álcool. Em resumo, para d'Almeida, a utilidade do argumento está em sua permissividade à omissão - ou dissimulação - das premissas nas quais o argumentador está confiando, ou deve confiar:

Com muita frequência, um argumentador que oferece um argumento a fortiori dirá explicitamente apenas que, dado que certa afirmação é verdadeira sobre a fonte, segue a fortiori que uma afirmação do mesmo tipo é verdadeira em relação ao alvo. Em outras palavras, os elementos que o argumentador apresentará são duas conclusões - uma sobre a fonte, a outra sobre o alvo - cabendo ao auditório discernir os argumentos subjacentes (tradução nossa) ${ }^{47}$.

Em resumo, o gênero de problema que as duas espécies de problemas representam tem relação com o fato de que esses esquemas não são fiéis à forma como o argumento a fortiori aparece na prática, ou seja, os esquemas são excessivamente exigentes com quem pretende avaliar o argumento, porque eles não descrevem o efetivo padrão de raciocínio do argumentador, nem reconhecem que há escassez de informações que tornam a reconstrução do argumento mais dialética do que lógica. Os teóricos deixaram seus esquemas muito expostos a objeções ao privilegiar a tradição lógica e subestimar o contexto da argumentação.

\subsection{UM ESQUEMA ALTERNATIVO}

Os problemas apresentados na seção anterior não afetam negativamente

${ }_{47}$ D'ALMEIDA, Luís Duarte. Op. cit., 2016, p. 224. No original: "Very often, an arguer who offers an a fortiori argument will explicitly say only that given that a certain claim is true of the source, it follows a fortiori that a claim of the same kind is true of the target. In other words, the elements that the arguer will put forth are two conclusions - one about the source, the other about the target - of underlying arguments that it will be for the audience to discern". 
tribunais e advogados, eles frequentemente argumentam a fortiori, como defende d'Almeida ${ }^{48}$, mas, do ponto de vista teórico, esses problemas são relevantes. D'Almeida ${ }^{49}$ está particularmente preocupado em dar consistência teórica ao argumento a fortiori, sem, no entanto, deixar de ser fiel à forma como o argumento aparece na prática: como uma aposta do argumentador no consenso do auditório quanto à premissa implícita (do argumento em função do contexto).

Por exemplo, para que a conclusão pela recusa do uísque seja dedutivamente válida e substancialmente sólida a partir do simples fato de que o amigo não tocou a cidra, seria preciso conjecturar acerca do motivo disso. D'Almeida ${ }^{50}$ diz que o primeiro ponto a ser notado é que o argumento compara duas coisas - cidra e uísque -, com o objetivo de predizer que, se o amigo bebe o primeiro, então ele também beberá o segundo; ou, se ele não bebe o primeiro, então também não beberá o segundo. Não há nada no argumento que indique porque ele bebe ou não; o argumento é caracteristicamente omisso sobre isso e pode ser reconstruído da seguinte forma:

(Argumento 7)

1. O amigo irá recusar a cidra.

(premissa explícita)

Então,

2. O amigo irá recusar o uísque. (conclusão)

Porém, só é possível garantir sua conclusão quando é possível entender o ponto dessa comparação. Como superar esse impasse? D 'Almeida ${ }^{51}$ defende que é inevitável "supor". Isso implica dizer que a tradição lógica e o contexto precisam ser deixados no mesmo plano, resgatando a importância do argumento a fortiori no processo decisório, como visto na primeira seção. Se o contexto em que o argumento está sendo apresentado deixa claro que a comparação diz respeito ao teor alcoólico das duas bebidas e, mais especificamente, o fato de que a cidra tem teor alcoólico menor do que o uísque, então o raciocínio por trás do argumento explícito é o de que: se o teor alcoólico da cidra é menor, mas ainda alto o suficiente para

\footnotetext{
${ }^{48}$ Ibidem, p. 202.

${ }^{49}$ Ibidem, p. 233-234.

${ }^{50}$ Ibidem, p. 204-205.

51 D'ALMEIDA, Luís Duarte. Op. cit., 2016.
} 
gerar a recusa do amigo, então, com mais razão, o uísque que tem teor alcoólico maior também será recusado.

$\mathrm{O}$ argumento a fortiori só começa a fazer sentido, no aspecto dedutivo, quando se rastreia e apresenta uma hipótese plausível e imputável ao argumentador como aquela com a qual ele contou para fazer sua afirmação. Esse é o caso da recusada cidra, em razão de seu teor alcoólico ${ }^{52}$. É possível dizer que o argumento $a$ fortiori é pouco exigente no momento de sua formulação, uma vez que o argumentador não tem o ônus de apresentar a hipótese com a qual ele se propõe a regular a relação entre os sujeitos e o predicado, ele pode deixar essa relação implícita. O ônus de extrair essa relação é de quem avalia o argumento.

Isso conduz a um importante ponto. Essa relação não se estabelece no campo do dever ser, e sim no campo do ser. O teor alcoólico não é um princípio implícito que diz como as coisas devem ser, ele é uma propriedade escalar que os sujeitos compartilham de maneira factualmente constatável. É um predicado que se pode ter em maior ou menor quantidade e ao qual se pode determinar um limiar relevante na escala: o ponto ou grau $T$ de teor alcoólico que, se atingido ou ultrapassado, então o amigo irá recusar a bebida. Para $D^{\prime}$ Almeida $^{53}$, essa premissa implícita de relação, e a cadeia de argumentos dedutivamente válidos, poderia ser estabelecida da seguinte forma pelo avaliador do argumento:

\section{(Argumento 8)}

1. Existe um ponto $T$ na escala de teor alcoólico que se uma bebida atinge, então o amigo recusa.

(premissa implícita)

2. A cidra atinge o ponto $T$.

Então,

3. O amigo irá recusar a cidra. (premissa explícita)

4. O uísque ocupa um lugar mais alto do que a cidra no ranking do teor alcoólico.

Então (de 2 e 4 se segue que),

5. $\mathrm{O}$ uísque supera o ponto $T$.

Portanto (de 1 e 5 se segue que), 
6. O amigo irá recusar o uísque.

(conclusão)

Se é verdade que o argumento 8 alcança uma conclusão dedutivamente válida, uma conclusão que é necessariamente verdadeira quando suas premissas são verdadeiras, também é verdade que ele se expõe mais a objeções quanto à verdade das premissas utilizadas nos diferentes passos da dedução. $\mathrm{O}$ argumentador precisou ou preferiu omitir premissas, e essa omissão pode envolver restrições epistêmicas do tipo: (i) falta de evidências que apoiem diretamente uma afirmação do tipo "o uísque atinge o ponto T"; (ii) falta de conhecimento do argumentador ou de sua audiência acerca de qual seja esse ponto $T$ na escala $R$ que permitiria deduzir a conclusão (recusa do uísque) sem recorrer à comparação (com a cidra) ou (iii) a falta de ambas as hipóteses. Ou restrições normativas, situações nas quais o argumentador entende ter razões suficientes para não tomar uma posição definitiva, de caráter normativo, sobre o que deve ser considerado como: (i) o ponto $T$ ou (ii) o lugar exato do caso-alvo na escala $R$ a partir da qual a decisão deve ser como a decisão no caso-fonte ${ }^{54}$. Em resumo, argumentos a fortiori são especialmente adequados para alcançar conclusões em contextos nos quais se deve determinar: (i) que um limite relevante foi atingido, mesmo que não se saiba exatamente que limite é esse, ou (ii) que existe uma regra para casos futuros que, em razão do contexto, não deve ser formulada explicitamente.

Feitas essas considerações iniciais sobre o esquema alternativo, é possível descrever e apresentar os termos nos quais ele é proposto. Contudo, antes, vale uma advertência: existe distinção importante entre um esquema que apenas explicita o padrão de raciocínio que o argumentador realmente usou, e não exige nenhum endosso ou complementação para sua reconstrução, e um esquema que busca constituir um padrão de argumento que seja válido ou convincente a partir da derivação do que efetivamente foi dito pelo argumentador. O esquema alternativo é desse segundo tipo, ele atribui à audiência a tarefa de discernir as premissas subjacentes que proporcionam validade e solidez ao raciocínio do argumentador. Reconstruir um argumento sob este paradigma depende então de um exercício que envolve supor as crenças que o argumentador tinha em mente, deveria ter tido em mente ou as crenças com as quais ele se comprometeu em virtude do que efetivamente disse. ${ }^{55}$

\footnotetext{
${ }^{54}$ Ibidem, p. 235.

55 SHECAIRA, Fábio P. How to Disagree About Argument Schemes. Informal Logic, v. 36, n. 4, 2016, p. 511.
} 
Como dito anteriormente, o ponto de partida para superar o problema da escassez de informações do argumento a fortiori depende da identificação de qual relação permite a comparação entre casos. D'Almeida ${ }^{56}$ propõe dois esquemas de reconstrução do argumento a fortiori para identificar qual é a propriedade escalar da classe de sujeitos $P$ que é relevante para a comparação - algo que indivíduos possam ter a mais, em igual medida, ou menos; e qual é o ponto ou grau $T$ nessa escala que uma vez ultrapassado garante que a conclusão pela predicação $S$ seja verdadeira. Todas informações que o argumentador não possuía ou não pretendeu revelar, mas que são importantes para a consistência do conjunto de decisões e por isso devem ser abstraídas. O sentido do primeiro esquema é de maior para menor (maiori ad minus), e o segundo de menor para maior (menor ad maius). Eles funcionariam da seguinte forma ${ }^{57}$ :

\begin{tabular}{|c|c|}
\hline Majori ad minus & Menor ad maius \\
\hline$(\text { Esquema 6) })^{2}$ & (Esquema 7) \\
\hline 1. Existe um ponto $T$ na escala de $P$ tal & 1. Existe um ponto $T$ na escala de $P$ \\
\hline que, para cada $x$, se $x$ atinge $T$ e não há & tal que, para cada $x$, se $x$ não atinge $T$ \\
\hline considerações relevantes em con- & e não há con \\
\hline trário, então $x$ é $S$. & em contrário, então $x$ é $S$. \\
\hline 2. $a$ atinge $T$. & 2. $a$ não atin \\
\hline la de $P, b$ está acima & $P, b$ está abaixo de $a$. \\
\hline Então (de $2 \mathrm{e}$ & Então (de 2 \\
\hline 4. $b$ atinge $T$ e não há considerações & 4. $b$ não atinge $T$ e não há considera- \\
\hline relevantes em contrário. & s em contrário. \\
\hline Então (de 1 e & Então (de 1 \\
\hline 5. $b$, com mais razão, é $S$. & 5. $b$, com mais razão, é $S$. \\
\hline
\end{tabular}

Como bem destaca D'Almeida ${ }^{58}$, dois aspectos desses esquemas podem parecer estranhos, dada sua crítica dirigida aos esquemas de Sion. O primeiro deles é o quão complexos são, quando comparados às efetivas afirmações dos argumentadores. Seria realmente plausível pensar que uma afirmação tão simples como a do Argumento 7 esconderia uma cadeia dedutivamente válida tão intrincada quanto a dos Esquemas 6 e 7 ? O segundo aspecto diz respeito à primeira premissa desses dois

\footnotetext{
56 D'ALMEIDA, Luís Duarte. Op. cit., 2016, p. 204.

57 Ibidem, p. 208, 211.

58 D’ALMEIDA, Luís Duarte. Op. cit., 2016, p. 224.
} 
esquemas. Identificar a propriedade escalar relevante a partir de argumentos reais pode não ser uma tarefa fácil, como pareceu ser no exemplo da cidra e do uísque. D'Almeida ${ }^{59}$ reconhece que há um descompasso entre o que os esquemas exigem e o que o argumentador efetivamente oferece na sua afirmação, mas ele não considera que isso seja uma falha desses esquemas. Para ele, esse descompasso é da natureza dos argumentos a fortiori, o argumentador pode não deixar claros os elementos cruciais implícitos na afirmação, ou pode não conhecer todos eles. O foco do argumento a fortiori está no auditório.

\section{UM EXEMPLO REAL DE ARGUMENTO A FORTIORI}

O debate sobre esquemas de argumentação geralmente envolve a discordância sobre a taxonomia, a classificação e as relações que os argumentos estabelecem. ${ }^{60}$ Como visto anteriormente, Macagno e Walton, Avi Sion e D'Almeida discordam quanto aos elementos e a estrutura do argumento a fortiori. Entretanto, não é incomum que juízes e advogados argumentem a fortiori para contornar certos tipos de restrições epistêmicas e normativas. As restrições processuais, a complexidade de um caso, e a proibição do non liquet parecem ser motivos suficientes para tornar intuitivo concluir que "aquele que pode fazer mais, também pode fazer menos" ou "aquele que não pode fazer menos, também não pode fazer mais".

Como esse tipo de argumento é usado por tomadores de decisão brasileiros?

É importante aduzir exemplos. O mecanismo de busca do Superior Tribunal de Justiça, a partir do termo "a fortiori", indica que, em maio de 2018, seis acórdãos de repetitivos, seiscentos acórdãos, dezesseis mil e trinta e seis decisões monocráticas, e dezessete informativos de jurisprudência recorreram a uma comparação deste tipo. ${ }^{61}$

Tendo em vista os limites do presente artigo, essa seção dedica-se à análise de dois dos seis acórdãos de repetitivos buscando destacar, principalmente: (i) o lugar que o argumento a fortiori ocupa no processo de tomada de decisão, se sua

\footnotetext{
${ }^{59}$ Ibidem, p. 224-225.

${ }^{60}$ SHECAIRA, Fábio P. Op. cit., 2016, p. 500.

${ }^{61}$ BRASIL. Superior Tribunal de Justiça. Jurisprudência do STJ. Brasília. 2018. Disponível em: < http://www.stj. jus.br/SCON/pesquisar.jsp > . Acesso em: 29 maio 2018.
} 
ordem de aparição ou maneira de estruturar apenas a adesão do auditório, ou se o argumento é usado para considerar o saldo dos fatos juridicamente relevantes em uma métrica comum, de modo a estabelecer que, se no caso precedente a decisão foi favorável à parte $P$, então com mais razão ela deve ser decidida em favor da parte que é análoga à $P$; e (ii) se o argumento $a$ fortiori real tem como característica a relação explícita entre os sujeitos como defendem Macagno, Walton e Sion, ou se esta relação deve ser abstraída do contexto pelo auditório como defende D'Almeida.

No Recurso Especial (Resp) no 1.144.079/SP, a Fazenda Nacional recorreu da decisão favorável ao depósito cautelar correspondente ao principal e acréscimos do imposto de importação devido sobre a depreciação de mercadorias solicitado pelo devedor antes da realização do reexame necessário pelo Tribunal. Nas razões recursais, a Fazenda alegou que houve violação da redação original do art. 475 do Código de Processo Civil de 1973, ao argumento de que "a sentença proferida no feito estava sujeita à disciplina do art. 475 , com a redação anterior àquela que lhe deu a [Lei n $\left.{ }^{0} 10.352 / 01\right]$, não havendo, por conseguinte, (...) qualquer restrição ao reexame necessário por parte do Tribunal" ${ }^{\prime 2}$. A Lei $n^{0} 10.532 / 01$ estabeleceu que somente as decisões de mérito cujo valor fosse superior a 60 salários-mínimos deveriam ser submetidas ao reexame necessário. A posição adotada pelo STJ foi a seguinte:

A adoção do princípio tempus regit actum, pelo art. 1.211 do CPC, impõe o respeito aos atos praticados sob o pálio da lei revogada, bem como aos efeitos desses atos, impossibilitando a retroação da lei nova. Sob esse enfoque, a lei em vigor à data da sentença regula os recursos cabíveis contra o ato decisório e, a fortiori, a sua submissão ao duplo grau obrigatório de jurisdição. ${ }^{63}$

$\mathrm{O}$ art. 475 original enunciava três hipóteses de cabimento do reexame de ofício. ${ }^{64} \mathrm{~A}$ segunda e terceira podiam ser reconduzidas a uma. $\mathrm{O}$ inciso II menciona-

${ }^{62}$ BRASIL. Superior Tribunal de Justiça. Recurso Especial n ${ }^{0} 1.144 .079$ - SP. Recorrente: Fazenda Nacional. Recorrido: Wilson Sons S/A Comércio Indústria e Agência de Navegação. Rel.: Min. Luiz Fux. Brasília, 2 de março de 2011. Disponível em: $<$ https://ww2.stj.jus.br/processo/revista/inteiroteor/?num_registro $=200901103794 \&$ dt_publicacao $=0 / 6 / 05 / 2011>$. Acesso em: 29 maio 2018.

${ }^{63}$ BRASIL. Superior Tribunal de Justiça. Recurso Especial no 1.144.079 - SP. Recorrente: Fazenda Nacional. Recorrido: Wilson Sons S/A Comércio Indústria e Agência de Navegação. Rel.: Min. Luiz Fux. Brasília, 2 de março de 2011. Disponível em: <https://ww2.stj.jus.br/processo/revista/inteiroteor/?num_registro $=200901103794 \&$ dt_publicacao $=0 / 6 / 05 / 2011>$. Acesso em: 29 maio 2018.

${ }^{64}$ Art. 475. Está sujeita ao duplo grau de jurisdição, não produzindo efeito senão depois de confirmada pelo tribunal, a sentença: I - que anular o casamento; II - proferida contra a União, o Estado e o Município; III - que julgar improcedente a execução de dívida ativa da Fazenda Pública (art. 585, número VI). Cf. BRASIL. Presidência da República. Lei $\mathrm{n}^{\circ}$ 5.869, de 11 de janeiro de 1973. Institui o Código de Processo Civil. Disponível em: <http://www.planalto.gov.br/ccivil_03/Leis/15869.htm>. Acesso em: 29 maio 2018. 
va as sentenças contrárias à Fazenda Pública e o inciso III referia-se às sentenças de procedência de embargos à execução fiscal. Como a execução fiscal apenas pode ser promovida pelo Fisco, as sentenças de procedência dos embargos à execução fiscal sempre são contrárias à Fazenda Pública. Ou seja, a hipótese do inciso III já estaria abrangida pela do inciso II.

Quanto ao lugar do argumento a fortiori no processo de tomada de decisão, fica claro um uso cujo objetivo não é considerar o saldo dos fatos juridicamente relevantes em uma métrica comum, e sim indicar que, se um princípio governa uma hipótese maior, então esse mesmo princípio também governa uma hipótese menor. $\mathrm{O}$ argumento a fortiori não limita a liberdade do tomador de decisão, ele busca a adesão do auditório.

Quanto à característica e estrutura desse argumento, ele parece mais aderente à ideia básica de Sion de que argumentos desse tipo ordenam termos, do que à ideia de Macagno e Walton de que ele fornece um princípio implícito, ou ainda à de D’Almeida, de que ele deixa não apenas a relação entre sujeitos implícita, mas também outros elementos cruciais importantes. A tentativa de reconstrução do argumento segundo o Esquema 1 de Macagno e Walton ${ }^{65}$ parece inapropriada em função da inexistência de duas categorias sendo comparadas. Existe um elemento $x$, que é o reexame necessário, um gênero $G$, que é o gênero dos recursos cabíveis contra ato decisório, e um predicado $S$, que é o duplo grau obrigatório. A falta de $P$ e $Q$ parece inviabilizar a reconstrução do argumento nestes termos.

Já o Esquema 6 de D’Almeida ${ }^{66}$ não parece aplicável, porque não há uma propriedade escalar em jogo. $\mathrm{O}$ argumentador invoca um princípio para resolver o caso a fortiori. Além disso, o auditório não precisa complementar o argumento com

\footnotetext{
65 (Esquema 1)

1. Nenhuma norma prevê que $x$ faz parte da categoria $Q$ (premissa alvo)

2. Se $x$ é $P$, então $x$ deve ser/é $S$. (premissa propriedade)

${ }^{3} P$ e $Q$ fazem parte/são um subconjunto do mesmo gênero funcional $G$ que motiva $S$. (premissa de similaridade)

4. Se $x$ é $G$, então $x$ deve ser/é $S$. (premissa espécie-gênero)

${ }^{5} Q$ pertence a $G$ com mais razão do que $P$ pertence a $G$.(premissa $a$ fortior $\left.i\right)$

Então,

${ }^{6}$ Se $x$ é $Q$, então $x$ deve ser/é $S$. (conclusão).

${ }^{66}$ (Esquema 6)

1. Existe um ponto $T$ na escala de $P$ tal que, para cada $x$, se $x$ atinge $T$ e não há considerações relevantes em contrário, então $x$ é $S$.

2. $a$ atinge $T$.

${ }^{3}$ Na escala de $P, b$ está acima de $a$.

Então (de 2 e 3),

4. $b$ atinge $T$ e não há considerações relevantes em contrário.

Então(de 1 e 5),

5. $b$, com mais razão, é $S$.
} 
informações que o argumentador não forneceu. Talvez o lugar do argumento $a$ fortiori nos moldes propostos por D'Almeida esteja no processo de tomada de decisão sobre fatos, e não sobre o direito. É preciso ampliar a quantidade de análises para poder estabelecer uma conclusão firme em qualquer sentido.

E como o argumento poderia ser reconstruído a partir do Esquema 2 de Sion? Veja-se:

\section{(Argumento 9)}

1. O reexame $(P)$ é tão recurso $(R)$ quanto qualquer outro recurso que a Fazenda Pública podia manejar em juízo, de acordo com a redação original do art. $475(Q)$.

2. Qualquer outro recurso que a Fazenda Pública podia manejar em juízo, de acordo com a redação original $(Q)$, era recurso $(R)$ o suficiente para estar sujeito ao duplo grau obrigatório (S).

Então,

3. O reexame $(P)$ está, com igual razão, sujeito ao duplo grau obrigatório $(S)$.

Esse argumento parece aderente ao que o argumentador efetivamente disse. Não foi preciso complementar a reconstrução com alguma informação extraída do contexto, mas qualquer afirmação no sentido de que essa é a forma de argumentar a fortiori mais comum seria precipitada. A posição do STJ na hierarquia dos tribunais, e o fato do recurso repetitivo ter uma função estabilizadora dentro do ordenamento, o que, consequentemente, exclui a determinação dos fatos desse argumento, podem ser indícios de que, talvez, esses diferentes esquemas não sejam concorrentes, e sim complementares. É preciso avançar nas análises para que seja possível verificar se existe um padrão de estrutura e contexto mais adequado para cada tipo de esquema.

\section{CONSIDERAÇÕES FINAIS}

A resposta parcial à pergunta que foi feita inicialmente parece ser positiva. O STJ, pelo menos, muitas vezes argumenta a fortiori, mas a afirmação teórica de que essa forma de argumentação é relevante por permitir que o julgador contorne 
certos tipos de restrições epistêmicas e normativas impeditivas do trato direto da questão ainda precisa ser confirmada. Por uma questão de escopo e espaço, o primeiro objetivo mais geral deste artigo era chamar a atenção para o lugar e a natureza desse tipo de argumento, principalmente, quanto ao que se pode aproveitar de uma convergência entre as abordagens lógica e dialética de argumentação.

A assunção de que o argumento a fortiori não é um argumento analógico, apesar de valer-se de semelhanças, permanece válida. É forçoso reconhecer que essa validez ainda é precária, mas correr o risco de uma invalidação posterior parece compensar a utilidade de uma distinção tão facilmente identificável: um argumento a fortiori não pretende estender o tratamento jurídico dispensado a uma categoria jurídica a elementos estranhos a essa categoria em função das características relevantes compartilhadas, e também não pretende extrair um princípio jurídico implícito aplicável a um gênero cujas espécies são os casos fonte e alvo.

A proposta de tentar fornecer evidências da utilidade do argumento a fortiori na instrumentalização do processo de tomada de decisão, principalmente em ambientes de grande incerteza, não pode ser verificada neste primeiro momento. Muito em função da necessidade de estabelecer quais seriam as bases da análise dos argumentos reais e do seu entorno. Nesse momento, mais do que analisar uma quantidade significativa de argumentos reais, importa compreender qual é a importância do contexto para a análise e quais são as diferentes propostas, algumas descritivas e outras normativas, de esquemas de argumentos a fortiori.

Acredita-se que o padrão estabelecido para a análise do Recurso Especial $\mathrm{n}^{\mathrm{o}}$ 1.144.079/SP, após a procura pelos dois critérios indicados no início da seção 4, e a partir do marco teórico apresentado nas seções anteriores, seja um padrão reproduzível em análises futuras, dando a consistência necessária para a verificação da existência de um padrão de estrutura e contexto que se mostre mais adequado para cada tipo de esquema argumentativo a fortiori: aquele que ordena termos, extrai princípios implícitos ou estabelece métricas comuns. 


\section{REFERÊNCIAS}

ALEXANDER, Larry. Constrained by precedent. South California Law Review, v. 63, p. 1-64, 1989.

BRASIL. Presidência da República. Lei $\mathbf{n}^{\mathbf{0}}$ 5.869, de 11 de janeiro de 1973. Institui o Código de Processo Civil. Disponível em: < http://www.planalto.gov.br/ccivil_03/ Leis/15869.htm > . Acesso em: 29 maio 2018.

BRASIL. Superior Tribunal de Justiça. Embargos de Declaração no Recurso Especial no 1.484.415 - DF. Embargante: Benedito Augusto Domingos. Embargado: Ministério Público do Distrito Federal e Territórios. Rel.: Min. Rogerio Schietti Cruz. Brasília, 3 de março de 2016. (2016a). Disponível em: < https://ww2.stj. jus.br/processo/revista/inteiroteor/?num_registro $=201402472885 \& d t$ publicacao $=14 / 04 / 2016>$. Acesso em: 18 out. 2017.

BRASIL. Superior Tribunal de Justiça. Jurisprudência do STJ. Brasília. 2018. Disponível em: < http://www.stj.jus.br/SCON/pesquisar.jsp > . Acesso em: 29 maio 2018.

BRASIL. Superior Tribunal de Justiça. Recurso Especial no 1.144.079 - SP. Recorrente: Fazenda Nacional. Recorrido: Wilson Sons S/A Comércio Indústria e Agência de Navegação. Rel.: Min. Luiz Fux. Brasília, 2 de março de 2011. Disponível em: < https://ww2.stj.jus.br/processo/revista/inteiroteor/?num_registro $=200901103794 \& d t$ publicacao $=0 / 6 / 05 / 2011>$. Acesso em: 29 maio 2018.

BRASIL. Supremo Tribunal Federal. Constitucional. Habeas Corpus no 126.292/ SP. Pcte.: Marcio Rodrigues Dantas. Coator: Relator do HC no 313.021 do Superior Tribunal de Justiça. Rel.: Min. Teori Zavascki. Distrito Federal, 17 de fevereiro de 2016 (2016b). Disponível em: < http://www.stf.jus.br/portal/processo/verProcessoAndamento.asp? numero $=126292 \&$ classe $=\mathrm{HC} \&$ codigoClasse $=0 \&$ origem $=\mathrm{JU}$ R\&recurso $=0 \&$ tipoJulgamento $=\mathrm{M}>$. Acesso em: 17 out. 2017.

D'ALMEIDA, Luís Duarte. Arguing a fortiori. The Modern Law Review, v. 80, n. 2, p. 202-237, 2016.

MACAGNO, Fabrizio; WALTON, Douglas. Arguments of statutory interpretation and argumentation schemes. International Journal of Legal Discourse, v. 2, n. 1, p. $47-83,2017$. 
RIEKE, Richard D.; SILLARS, Malcolm Osgood; PETERSON, Tarla Rai. Argumentation and critical decision making. New York: Longman, 1997.

SHECAIRA, Fábio Perin. How to Disagree About Argument Schemes. Informal Logic, v. 36, n. 4, p. 500-522, 2016.

SION, Avi. A Fortiori Logic: innovations, history and assessments. Genebra: Avi Sion, 2013.

VALENCIA MARTÍNEZ, Sandra C. The use of arguments a fortiori in decision making. 2016. Disponível em: < https://scholar.uwindsor.ca/cgi/viewcontent.cgi?referer $=$ https: $/ /$ scholar.google.com.br $/ \&$ httpsredir $=1 \&$ article $=2447 \&$ context $=$ ossaarchive > . Acesso em: 13 maio 2018.

VAN EEMEREN, F. H. Strategic maneuvering in argumentative discourse: Extending the pragma-dialectical theory of argumentation. Amsterdam: John Benjamins Publishing, 2010.

WISEMAN, Allen. A contemporary examination of the a fortiori argument involving jewish traditions. 2010. 257f. Tese de Doutorado em Filosofia. Universidade de Waterloo, Ontario. Disponível em: < https://uwspace.uwaterloo.ca/bitstream/handle/10012/5038/A\%20Contemporary\%20Examination\%20of\%20the $\% 20$ A\%20Fortiori\%20Argument\%20Involving\%20Jewish\%20Traditions.pdf?sequence $=1>$. Acesso em: 22 maio 2018.

Recebido em: 03/07/2018 Aceito em: 28/09/2018 